\title{
Microstructural Analysis and Strength Development of One-Part Alkali-Activated Slag/Ceramic Binders Under Different Curing Regimes
}

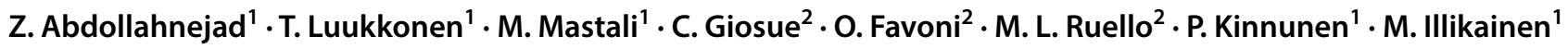

Received: 1 September 2018 / Accepted: 14 February 2019 / Published online: 25 February 2019

(c) The Author(s) 2019

\begin{abstract}
Alkali-activated binders have shown great potential in the reuse of industrial waste materials and have therefore received significant attention. The use of one-part or a "just-add-water" alkali-activated binder aims to avoid the use of alkali-activator solutions which have traditionally been utilized in two-part systems. By using a solid activator, the disadvantages posed by hazardous liquid activators (such as the difficulties of using them on-site) can be minimized. Ceramic materials represent a considerable fraction of construction and demolition wastes, and originate not only from the building process, but also as tiles from industry and rejected bricks. Besides using these waste materials as road sub-base or construction backfill materials, they can also be employed as supplementary cementitious materials or even as raw material for alkali-activated binders. This paper presents the strength development and microstructural results obtained from examining different compositions under various curing conditions (sealing, ambient, and submerged in water). Two different ceramic wastes (with and without firing) were used as a partial replacement ( $5-10 \%$ by mass) of ground granulated blast-furnace slag. Specimens were then cured under three different curing regimes, including: (1) plastic-sealed, (2) unsealed at ambient conditions with an average temperature of $23{ }^{\circ} \mathrm{C}$ and $35 \% \mathrm{RH}$, and (3) submerged in water until the test date. Mechanical testing (compressive and flexural strengths) and microstructural analysis (SEM/EDX, XRD, MIP, heat of hydration, TGA, and DTA) were used to determine the effects of curing conditions. The results showed that ceramic waste content and type, as well as curing regimes, greatly affect the chemical reaction products, strength development, and structural stability.
\end{abstract}

Keywords One-part alkali-activated binders $\cdot$ Ceramic wastes $\cdot$ Curing conditions $\cdot$ Mechanical properties

\section{Statement of Novelty}

This paper presents the effects of using three different curing conditions (sealed, ambient, and submerged in water) on strength development at early and final ages and the microscopic analysis of one-part alkali-activated slag/ceramic binders. Moreover, a comparative study is conducted on partial replacement of ground granulated blast-furnace slag by two different ceramic wastes as a binder type.

Z. Abdollahnejad

Zahra.abdollahnejad@oulu.fi

1 Fibre and Particle Engineering, Faculty of Technology, University of Oulu, P.O. Box 4300, 90014 Oulu, Finland

2 Department of Materials, Environmental Sciences and Urban Planning - SIMAU, Università Politecnica delle Marche, UdR INSTM, 60131 Ancona, Italy

\section{Introduction}

Ordinary Portland cement (OPC) has the highest consumption rate as a binder in the construction industry due to acceptable mechanical and durability performance [1]. The production process of OPC generates a large amount of $\mathrm{CO}_{2}$, such that the production of 1 ton of OPC results in the release of 1 ton of $\mathrm{CO}_{2}$ into the atmosphere [2]. The resulting release of $\mathrm{CO}_{2}$ can be counted as one of the main contributors in greenhouse gas (GHG) emissions and should therefore be the subject of efforts to minimize negative environmental impacts. The application of technologies and any kind of developments that can result in reducing GHG emission have recently received significant attention.

Alkali-activated binders represent an alternative class of cementitious compositions and have been the subject of significant interest as a consequence of global requirements to reduce environmental impacts [3]. These binders are usually prepared by mixing precursors and an alkali-activator 
solution [4]. Due to the disadvantages of employing alkaliactivator solutions and especially because of the challenges posed by handling the corrosive, viscous and hazardous liquids at a large scale, the development of the one-part or just-add-water concept has received significant attention [5]. One-part alkali-activated materials demonstrate greater potential to be used for cast-in-situ applications compared to two-part alkali-activated materials. The preparation of onepart alkali activated materials is similar to OPC based compositions as it consists of different aluminosilicate precursors, alkali sources and possible admixtures in solid shape and water is added in the last step [6]. Developing of onepart alkali-activated materials facilitates the commercialization of these alternative binders in the construction industry.

As mentioned earlier, different precursors are used for the preparation of alkali- activated binders such as industrial by-products, including granulated blast furnace slag (derived from the steel making industry), fly ash (derived from coal or biomass combustion), and clays (metakaolin) $[7,8]$. Recently, various efforts have been made to use natural pozzolans in alkali activated binders $[9,10]$.

Different studies have reported the potential of using slag in alkali-activated materials as they are categorized as a calcium-rich aluminosilicate precursor [11], which results in rapid setting [12], high strength [13, 14], low hydration heat [15], high temperature resistance [15], and lower $\mathrm{CO}_{2}$ emissions [16-19] compared to OPC compositions. In addition to alkali solution properties, the content of slag has crucial impacts on these parameters in alkali activated binders. Based on the investigations executed by Najimi et al., the strength developments of alkali-activated natural pozzolan/ slag mortars have enough potential to reach the cementitious compositions [20]. However, these alternative binders indicated lower chloride penetration depth and higher drying shrinkage than OPC compositions [20].

In addition to the positive mechanical characteristics of using slag in the alkali-activation process, there are some unfavorable aspects associated with using slag, such as volumetric instability and high shrinkage compared to OPC, and these drawbacks limit its utility in the construction industry [21]. Various studies have demonstrated that the combination of slag as a high-calcium-level precursor with another low-calcium-level precursor reduces shrinkage compared to alkali-activated binders solely containing slag [22-33].

Recently, ceramic waste has been proposed as a silica source in the preparation of alkali-activated binders due to its high content of silica [34]. In addition to the content of active calcium in the mix composition (which plays an important role in gel formation and strengthening), the content of reactive silica and alumina are important in the formation of the gel structure [5]. If one includes rejected tiles, bricks, and other items from industry, it is estimated that almost $45 \%$ of construction and demolition wastes are ceramics, which represents a large amount of recyclable material [34]. Based on a published review by Zimbili et al. [35], 9 million $\mathrm{m}^{3}$ of ceramics were produced in 2010, of which 30 major manufacturing countries are responsible for $96 \%$ of the production.

Thus, the use of ceramic waste as a silica source in the preparation of alkali-activated binders could have some advantages, including the conservation of natural resources, and energy as well as reductions in $\mathrm{CO}_{2}$ emissions and other greenhouse gases, and economic advantages. Accordingly, the use of ceramic waste as a partial replacement for binders has been the subject of several studies [36-41]. Based on results reported by Puertas et al. [42], the maximum compressive strength obtained from ceramic wastes activated by sodium hydroxide and sodium silicate solutions with 8 days curing at a temperature of $40{ }^{\circ} \mathrm{C}$ was around $13 \mathrm{MPa}$ [42].

Reig et al. [43] investigated the effect of activating solutions on the compressive strength of pastes and mortars composed of clay brick wastes and activated by sodium hydroxide and sodium silicate solutions [43]. The highest compressive strength was $50 \mathrm{MPa}$ after 7 days of curing at $65{ }^{\circ} \mathrm{C}$. Moreover, another study was conducted by Reig et al. [34] to investigate the effects of activating solution concentration on mechanical strength and microstructure using two ceramic waste materials (porous red-clay brick and porcelain stoneware) with very different sintering temperatures and chemical compositions [34]. The maximum compressive strengths of $41 \mathrm{MPa}$ and $30 \mathrm{MPa}$ after 7 curing days at $65{ }^{\circ} \mathrm{C}$, were reported for the red clay brick powder and porcelain stoneware, respectively [34].

The high-energy consumption and low production efficiency associated with high-temperature curing restrict the scope of its applications. Extensive research on the development of alkali-activated hybrid blended binders incorporating slag and another precursor has been conducted, but very limited information has been published regarding the effects of using ceramic waste type and content as a precursor on the mechanical properties and microstructural analysis under different curing regimes. If satisfactory mechanical properties can be obtained with minimum energy consumption, this would not only facilitate the use of one-part alkali-activated slag/ceramic binders, but could also reduce cost as well as $\mathrm{CO}_{2}$ emissions.

No extensive study has been performed on clarifying the effects of using several ceramics in one-part alkali activated binders under different curing conditions on strength development and the microscopic analysis. To facilitate the commercialized usage of one-part alkali activated materials, it is required to reach the maximum strength with minimum required energy for curing. Moreover, it is necessary to minimize the possibility of forming cracks due to high drying shrinkage in alkali activated slag based binders considering the minimum strength reduction. Therefore, all efforts 
were made in this paper to obtain the maximum strength in one-part alkali activated slag based binders using different ceramic types and contents. Using different ceramic sources from constructional demolished-wastes provides different chemical reactivates, which impact differently on the strength and chemical reactions under different curing conditions. Therefore, in this study, three different curing regimes (sealed, ambient, and submerged in water) were used to cure the specimens, and their flexural and compressive strengths were assessed at the ages of 7, 14, and 28 days. In this investigation, the differences in the raw (unfired) and porcelain (fired) ceramics were derived from using glaze to cover the surface of ceramics. This coating layer, which is used for porcelain ceramics, is a vitreous substance, which has been fused to a ceramic body through firing. It will be shown that both ceramic wastes have almost similar chemical compositions.

\section{Experimental Program}

\section{Materials and Mix Designs}

The designed mix compositions are comprised of ground granulated blast-furnace slag (GGBFS), ceramic waste (porcelain or raw), fine aggregate, anhydrous sodium silicate $\left(\mathrm{Na}_{2} \mathrm{SiO}_{3}\right)$ with silica modulus of $\mathrm{SiO}_{2} / \mathrm{Na}_{2} \mathrm{O} \approx 0.9$ and tap water with low hardness. Finnish sanitary ware manufacturer, IDO, provided ceramic waste materials. The slag was received from Finnsementti (Finland), which supplies it as a supplementary cementitious material. The used slag had a particle size $d_{50}$ value and density of $10.8 \mu \mathrm{m}$ and $2.93 \mathrm{~g} /$ $\mathrm{cm}^{3}$, respectively.

The chemical composition of the used ground granulated blast-furnace slag, porcelain and raw ceramic wastes were determined by X-ray fluorescence (XRF) and are presented in Table 1.

Ceramic wastes were classified by type and production process as described by Pacheco-Torgal and Jalali [44]. Regarding the proposed classifications, there are two groups in accordance with the source of raw materials: white and red pastes [44]. According to this classification, all ceramic wastes are fired and the differences are governed by the firing times (i.e. once or twice). The fired wastes generated by the structural ceramic factories use only red pastes to manufacture their products, such as brick, blocks and roof tiles. The second fired ceramic waste produced in stoneware ceramic include materials such as wall, floor tiles and sanitary ware [44].

The chemical compositions were determined with a 4-kV wavelength dispersive X-ray fluorescence (XRF) spectrometer (PANalytical AxiosmAX). XRF analyses were performed from fused samples: $1.5 \mathrm{~g}$ of sample was melted at $1150{ }^{\circ} \mathrm{C}$
Table 1 The chemical composition of slag and ceramic wastes (porcelain and raw) as determined with XRF

\begin{tabular}{lrrr}
\hline $\begin{array}{l}\text { Element/oxide, } \%, \\
w / w\end{array}$ & GGBFS & $\begin{array}{l}\text { Fired ceramic } \\
\text { waste }\end{array}$ & $\begin{array}{l}\text { Unfired } \\
\text { ceramic } \\
\text { waste }\end{array}$ \\
\hline $\mathrm{Na}_{2} \mathrm{O}$ & 0.51 & 2.202 & 2.005 \\
$\mathrm{MgO}$ & 10.24 & 0.316 & 0.134 \\
$\mathrm{Al}_{2} \mathrm{O}_{3}$ & 9.58 & 21.017 & 20.965 \\
$\mathrm{SiO}_{2}$ & 32.33 & 67.066 & 64.879 \\
$\mathrm{P}_{2} \mathrm{O}_{5}$ & 0.01 & 0.079 & 0.086 \\
$\mathrm{SO}_{3}$ & 4.00 & 0.024 & 0.026 \\
$\mathrm{~K}_{2} \mathrm{O}$ & 0.53 & 2.326 & 2.256 \\
$\mathrm{CaO}$ & 38.51 & 1.450 & 0.301 \\
$\mathrm{Cr}_{2} \mathrm{O}_{3}$ & 0.00 & 0.047 & 0.015 \\
$\mathrm{MnO}$ & 0.00 & 0.022 & 0.000 \\
$\mathrm{Fe}_{2} \mathrm{O}_{3}$ & 1.23 & 0.853 & 0.524 \\
\hline
\end{tabular}

Fired ceramic waste*: Porcelain ceramic waste

with $7.5 \mathrm{~g}$ of X-ray Flux Type $66: 34\left(66 \% \mathrm{Li}_{2} \mathrm{~B}_{4} \mathrm{O}_{7}\right.$ and $34 \%$ $\mathrm{LiBO}_{2}$ ) to obtain melt-fused tablets.

A grain-size distribution was obtained for sand grains based on the ASTM D6913 recommendation [45], in which sand grains were distributed between the minimum and maximum grain sizes of $0.2 \mathrm{~mm}$ and $1.6 \mathrm{~mm}$, respectively. A constant ratio of 2 was used for sand to binder in this paper. Ghafoori et al. showed that using a sand to binder ratio around 2 results in obtaining high strength for green concretes [10]. Moreover, both raw and porcelain ceramic wastes were milled to obtain a grain size less than $0.5 \mathrm{~mm}$ $\left(\mathrm{d}_{50}<18 \mu \mathrm{m}\right)$.

\section{Specimen Synthesis and Ageing}

In the batching process, slag, ceramic waste, sodium silicate, and sand were initially combined for $3 \mathrm{~min}$ in a mixer. Tap water was then added to the mixture and again stirred for a further 2 min. Afterwards, fresh mortar was cast into cubic molds $(40 \times 40 \times 40 \mathrm{~mm})$ and prismatic beams $(40 \times 40 \times 160 \mathrm{~mm})$ to assess physical and mechanical properties, including water absorption, the compressive strength, and the flexural strength. The results were analyzed and evaluated by using the average of three tested specimens.

After casting, the specimens were kept for $24 \mathrm{~h}$ at a temperature of $23{ }^{\circ} \mathrm{C}$ and relative humidity of $35 \%$ and specimens were then demolded and cured in three different regimes including: (1) submerging in water with temperature of $20^{\circ} \mathrm{C}$, (2) sealing with plastic bags, and (3) ambient curing conditions with a temperature of $23{ }^{\circ} \mathrm{C}$ and $35 \%$ relative humidity until the test day (the cured specimens were called "unsealed"). Since one of the main aims of this study was not to use thermal curing conditions, this curing method was not used. Concerning 
Table 2 The proportions of the mix compositions

\begin{tabular}{lllllll}
\hline Mixtures & Slag (\%) & $\begin{array}{l}\text { Porcelain } \\
\text { ceramic }(\%)\end{array}$ & $\begin{array}{l}\text { Raw } \\
\text { ceramic (\%) }\end{array}$ & Sand/binder & $\begin{array}{l}\text { Sodium } \\
\text { silicate (\%) }\end{array}$ & Water/binder \\
\hline Reference & 90 & 0 & 0 & 2 & 10 & 0.35 \\
PCW5 & 85 & 5 & 0 & 2 & 10 & 0.35 \\
RCW5 & 85 & 0 & 5 & 2 & 10 & 0.35 \\
PCW10 & 80 & 10 & 0 & 2 & 10 & 0.35 \\
RCW10 & 80 & 0 & 10 & 2 & 10 & 0.35 \\
\hline
\end{tabular}

Table 3 Setting times of the mix compositions

\begin{tabular}{lll}
\hline Mixtures & Initial setting time (min) & $\begin{array}{l}\text { Final setting } \\
\text { time }(\mathrm{min})\end{array}$ \\
\hline Reference & 20 & 28 \\
PCW5 & 40 & 50 \\
RCW5 & 35 & 42 \\
PCW10 & 42 & 53 \\
RCW10 & 38 & 45 \\
\hline
\end{tabular}

ceramic waste types and contents, five different compositions were designed, for which the mixture designations and proportions are provided in Table 2 . The reference mix composition in Table 2 was chosen based on the investigations Luukkonen et al. [9]. Regarding the usage of three different curing regimes, in total 45 prismatic beams for assessing the flexural strength were cast and tested based on the ASTM C116-90 recommendation [46]. A portion of the samples from the flexural test were used for assessing the compressive strength based on the ASTM C116-90 recommendation.

In addition to investigate the impacts of using ceramic wastes on the hardened state properties, the effects of replacing slag with ceramic wastes were studied. The initial and final setting times of 20 and 28 min were recorded by a Vicat apparatus for the reference mixture with $100 \%$ slag, respectively, which are short time for real applications. Thus, it was assumed that using ceramic wastes could prolong the setting time. Table 3 listed the influences of using ceramic wastes instead of slag on the initial and final setting times. As mentioned in Table 3, the addition of ceramic wastes (regardless of the ceramic waste type) prolonged the initial setting times longer than $30 \mathrm{~min}$. Therefore, slag was replaced with 5\% and $10 \%$ ceramic wastes in the mix compositions.

In the present study, the main aim was to investigate the influences of using different curing regimes on the physical, mechanical, and microstructural properties of one-part alkali-activated slag/ceramic binders. The molar ratios of the proposed mix compositions (assuming total solubility of raw materials) were computed and are presented in Table 4. According to the calculated molar ratios, the main difference between compositions was in the molar ratios of $\mathrm{CaO} /$
Table 4 Molar ratios of the mix compositions

\begin{tabular}{lllll}
\hline Molar ratios & \multicolumn{3}{l}{} \\
\hline Mixtures & $\mathrm{SiO}_{2} / \mathrm{Al}_{2} \mathrm{O}_{3}$ & $\mathrm{Na}_{2} \mathrm{O} / \mathrm{SiO}_{2}$ & $\mathrm{Na}_{2} \mathrm{O} / \mathrm{Al}_{2} \mathrm{O}_{3}$ & $\mathrm{CaO} / \mathrm{SiO}_{2}$ \\
\hline Reference & 6.57 & 0.16 & 1.04 & 1.10 \\
PCW5 & 6.49 & 0.15 & 0.99 & 0.99 \\
PCW10 & 6.41 & 0.15 & 0.95 & 0.89 \\
RCW5 & 6.46 & 0.15 & 0.99 & 0.99 \\
RCW10 & 6.36 & 0.15 & 0.94 & 0.89 \\
\hline
\end{tabular}

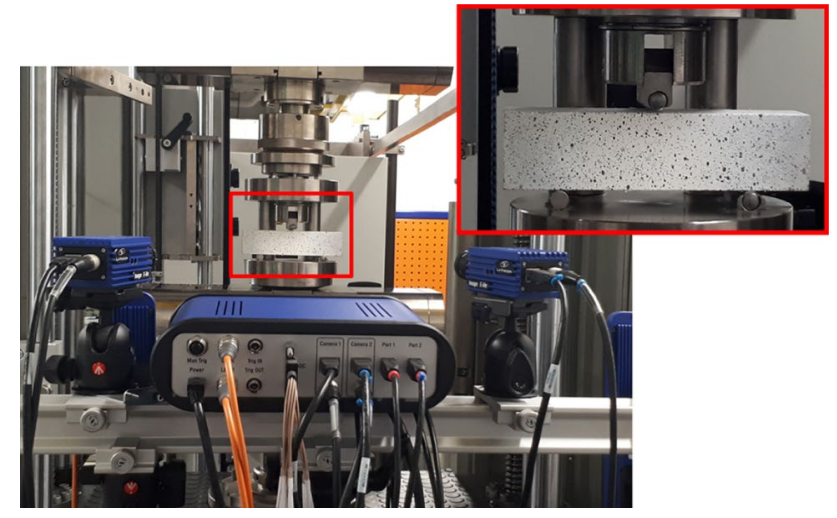

Fig. 1 Adopted test setup for executing flexural test

$\mathrm{SiO}_{2}$, in which the difference mainly arises from the partial replacement of slag with ceramic wastes.

\section{Test Procedures and Setups}

\section{Three-Point Bending Test (TPB)}

In total, forty-five prismatic beams with dimensions of $40 \times 40 \times 160 \mathrm{~mm}$ were employed to assess the flexural performance of the beams made with one-part alkali-activated slag/ceramic binders under a three-point bending (TPB) test in accordance with the ASTM C293 recommendation [47]. As shown in Fig. 1, the flexural load was recorded by using a wick, Z100 Roell testing machine with a load cell of $100 \mathrm{kN}$ capacity. For each mix composition, three prismatic beams were cast, prepared and tested with a constant flexural load 
speed of $0.6 \mathrm{~mm} / \mathrm{min}$. The flexural load was submitted to the beams under a displacement control. Equation (1) was used to calculate the flexural strength of specimens under the TPB test:

$\sigma_{f}=\frac{3 F L}{2 b h^{2}}$

where $F$ is the total flexural load, $L$ is span length, $b$ and $h$ are width $(40 \mathrm{~mm})$ and height $(40 \mathrm{~mm})$ of beams, respectively.

\section{Compressive Test}

As mentioned, three different regimes were used to cure the specimens. According to the ASTM C116-90 recommendation, the compressive strength of concrete was measured by using the portions of prismatic beams broken in flexural tests. All the broken prismatic beams were assessed under a compressive load with constant speed of $1.8 \mathrm{~mm} / \mathrm{min}$. The results were obtained from the average of six tested specimens.

\section{The Permeable Porosity}

The effects of different curing regimes on the permeable porosity was calculated based on the concept of weight gain due to water absorption and weight loss because of buoyancy. Forty-five cubic specimens with an edge of $40 \mathrm{~mm}$ were cast and cured for 28 days under the aforementioned conditions. The cubic specimens were then immersed in a water tank (the average water temperature was $20^{\circ} \mathrm{C}$ ) at room temperature for $24 \mathrm{~h}$. Afterward, the specimens were removed from the water and placed on wire mesh for $1 \mathrm{~min}$ to allow the water to drain. Then, by using a damp cloth, the visible surface water was removed and the mass was recorded as $W_{S}$ (saturated weight). Afterward, the buoyant mass of the saturated specimen in water was measured $\left(W_{B}\right.$ : Buoyant mass). All specimens were placed in an oven at $105^{\circ} \mathrm{C}$ for not less than $24 \mathrm{~h}$. The masses of specimens were measured every two hours. The increment of the mass loss should not be greater than $0.1 \%$ of the last mass, which was measured for the specimen. The mass of the dried specimens was obtained as $W_{D}$ (oven-dry weight). The permeable porosity could be obtained by the following equation:

Permeable porosity $=\frac{W_{S}-W_{D}}{W_{S}-W_{B}}$

\section{Microstructural Analysis}

After assessing the strength development, the morphology and identification of the chemical compounds were investigated by scanning electron microscopy (SEM) and energydispersive X-ray spectroscopy (EDX), respectively.
To take SEM images, some small hardened parts of the mixtures were selected and submerged in acetone (ACS grade) to stop hydration. The SEM produces and scans a finely focused beam of electrons, which scans across the specimen and records the signals resulting from the interaction of the electron beam and specimen. In this study, the SEM images (SEM-EDS, Zeiss Ultra Plus) were provided by using an acceleration voltage of $15 \mathrm{kV}$; distance varied in the range of 6-8 $\mathrm{mm}$.

$\mathrm{X}$-ray diffraction (XRD) analysis was performed to investigate the crystalline phases of the specimens and the effects of different curing regimes on phase identification of the crystalline materials. The XRD data were collected by using a Bruker D8 Advance X-ray diffractometer with Ni-filtered $\mathrm{Cu}$ k $\alpha$ radiation $(1.54 \AA$ ) at $40 \mathrm{~mA}$ and $40 \mathrm{kV}$. The scan rate of $0.5 \mathrm{~s}$ per step was used to perform the scanning process of each sample from $13^{\circ}$ to $90^{\circ}$. Using the ICDD PDF4 database from the International Center for Diffraction Data, the phase identification was performed by comparing the different patterns to identify the phases. The phase identification was performed by Jade 7 software, version 5.1.2600, from Materials Data Inc. It is worth stating that this analysis was carried out using the pastes.

The term "porosimetry" is often used to include the measurements of pore size, volume, distribution, density, and other porosity-related characteristics of a material. Porosity is especially important in understanding the formation, structure, and potential use of many materials. The porosity of a material affects its physical and mechanical properties. The adsorption, permeability, strength, density, and other factors influenced by a substance's porosity determine the manner and fashion in which it can be appropriately used. The Mercury Intrusion Porosimetry (MIP) technique is widely used to measure the change in the porosity of specimens exposed to different curing conditions. To execute this measurement, after 28 days of curing (in water, sealed and unsealed) some fragments of about $1 \mathrm{~cm}^{3}$ were sampled from bulk of specimens. They were immersed in ethanol for $2 \mathrm{~h}$ in order to stop the hydration of paste and then dried in an oven with temperature of $110^{\circ} \mathrm{C}$ for $2 \mathrm{~h}$. The MIP test was performed by using a Thermo Fisher, Pascal series 240 .

To study the reaction products and the conversion processes, a thermogravimetric analysis (TGA) and differential thermogravimetry (DTG) were carried out on the 28-day paste samples using the Precisa Gravimetrics AG "prepASH automatic drying and washing system." The samples were crushed and heated up to $1000{ }^{\circ} \mathrm{C}$ at $10^{\circ} \mathrm{C} / \mathrm{min}$ in a nitrogen atmosphere.

A heat of hydration test was used to understand the role of replacing slag with different ceramic waste content and type on the hydration kinetics of mix compositions. The heat of hydration data was continuously measured from $2 \mathrm{~min}$ after completion of mixing and then measured for $46 \mathrm{~h}$ at 
about $20^{\circ} \mathrm{C}$ using a semi-adiabatic calorimeter (F-Cal 8000, Calmetrix). To execute this test, different pastes with fresh mixture weights of $200 \mathrm{~g}$ were sealed in plastic vials and placed into the calorimeter.

\section{Results and Discussion}

\section{Flexural Strength}

Based on the designed experimental procedure to evaluate the effect of replacement of slag with $5 \%$ or $10 \%$ of two different ceramic wastes (porcelain ceramic and raw ceramic waste) on the flexural strength, 45 prismatic beams with dimensions of $40 \times 40 \times 160 \mathrm{~mm}$ were cast and tested (see Fig. 1). According to the results presented in Fig. 2, regardless of ceramic waste content and type, specimens cured at the sealed and at the ambient conditions (unsealed) showed the maximum and minimum flexural strength, respectively. Replacing waste ceramic with slag reduced the flexural strength for the sealed specimens, while the flexural strength was slightly increased when specimens were submerged in water. This finding could be explained by the effect that the curing conditions had on porosity and polycondensation. It will be discussed later (in "The Permeable Porosity" section) how curing regime affects the porosity by MIP test. At the early age (7 days), the maximum flexural strength is attributed to the reference mix composition having been cured at ambient temperature (around $8 \mathrm{MPa}$ ), and the minimum was related to the mixture incorporating $10 \%$ raw ceramic waste and having been cured at the ambient conditions (unsealed). It was noted that replacing slag with ceramic waste slightly reduced the flexural strength in the sealed beams with plastic bags, while curing at ambient conditions (unsealed) and with water barely enhanced the flexural strength with increasing ceramic waste content.

Moreover, it was interesting to find that the use of ceramic waste reduced the minimum and maximum strength differences under different curing conditions. On the other hand, the sensitivity for curing conditions reduced with increasing ceramic waste content.

In addition, using fired ceramic waste led to slightly higher flexural strength compared to raw ceramic waste, which could be explained by the formation of more reaction products. By increasing the curing time from 7 to 14 days, no great change was observed in the development of the flexural strength. With an increase in the curing time from 7 to 28 days, a strength gain was observed in the mixtures, (a)

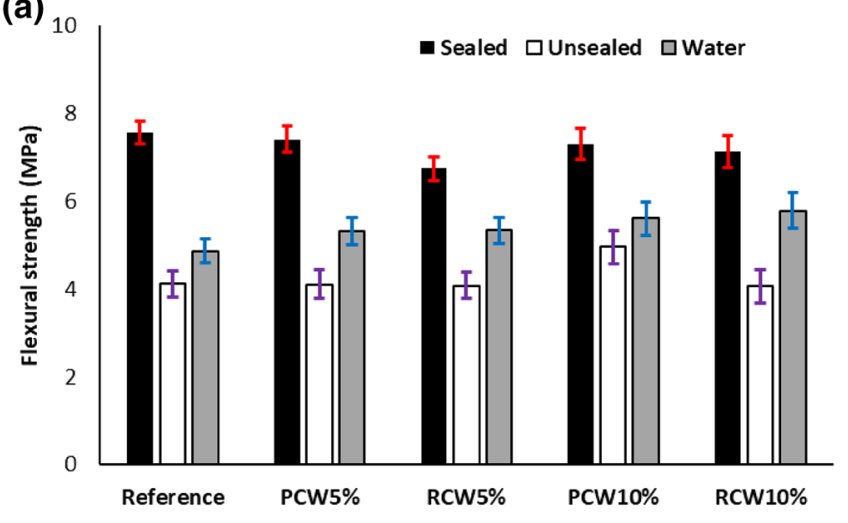

(b)

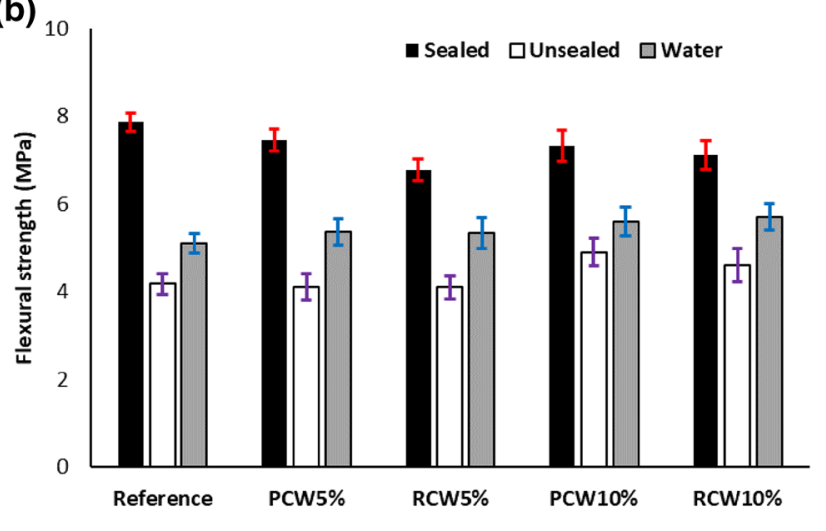

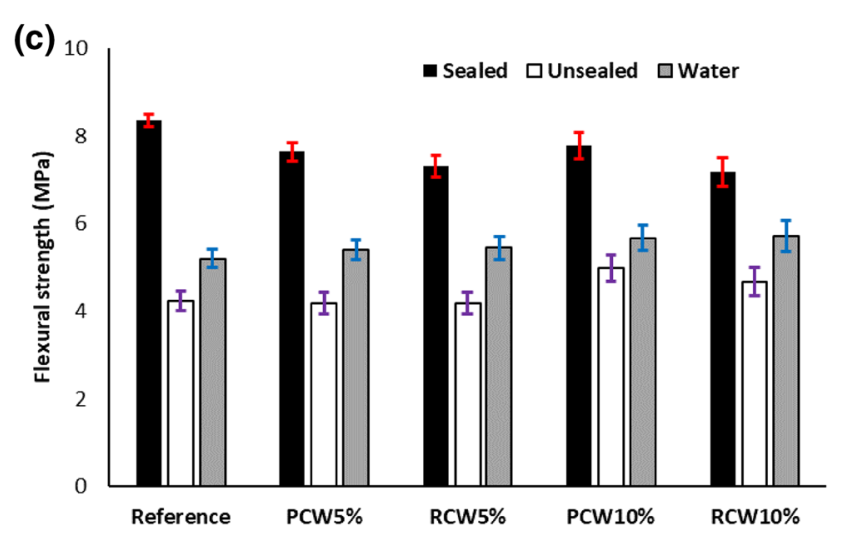

Fig. 2 Effects of replacing slag by two different ceramic wastes on the flexural strength at: a 7 days, b 14 days, c 28 days 
which was governed by the curing approach. With regard to the results, the greatest enhancement in flexural strength was observed in the cured specimens through sealing with plastic bags, and the maximum improvement was around $10 \%$. Using plastic bags reduces the water evaporation and effects on the temperature-dependent chemical reactions [48] and makes the formation of the chemical reactions faster.

At the age of 28 days, the maximum flexural strength was around $9 \mathrm{MPa}$ for the sealed reference mix composition and the minimum was attributed to the unsealed composition incorporating 5\% raw or fired ceramic waste, and was around $4 \mathrm{MPa}$. These results confirmed that the best curing condition in terms of increasing the strength among the proposed curing regimes was sealing. The highest flexural strength was registered for the sealed specimens and the lowest strengths were observed for the compositions cured at the ambient temperature (unsealed). Moreover, replacing slag by ceramic waste showed that using both raw and fired ceramic waste did not greatly affect the flexural strength development. Suwan and Fan demonstrated that the generated heat from the dissolution of solid activators in one-part geopolymers could positively affects the curing process and sealing with plastic bag could reduce dehydration in alkali activated binders [49]. Luukkonen et al. [6] proposed that sealing with plastic is commonly the most preferable curing technique in one-part alkali activated binders to reach the maximum strength. Ghafoori et al. [10] conducted a comparative study to assess the effects of using different curing conditions in geopolymers. It was also confirmed that the sealed curing conditions had the maximum impact to strength gain.

\section{Compressive Strength}

The influence of using different curing approaches on compressive strength is shown in Fig. 3. According to the results obtained, the compressive strength at the early age was found to be more than $55 \mathrm{MPa}$ for all the compositions cured and sealed for 7 days. Similar to the flexural strength, the strength development showed high sensitivity to curing conditions, so that the compressive strength decreased from 55 to $35 \mathrm{MPa}$ when the curing approach was changed from sealing to unsealing (around a 40\% strength reduction). Although using water to cure the specimens resulted in an enhancement of compressive strength compared to curing at ambient conditions, the maximum improvement was roughly $15 \%$ in the composition containing $10 \%$ fired ceramic waste and $30 \%$ in the reference mixture. Moreover, it was noted
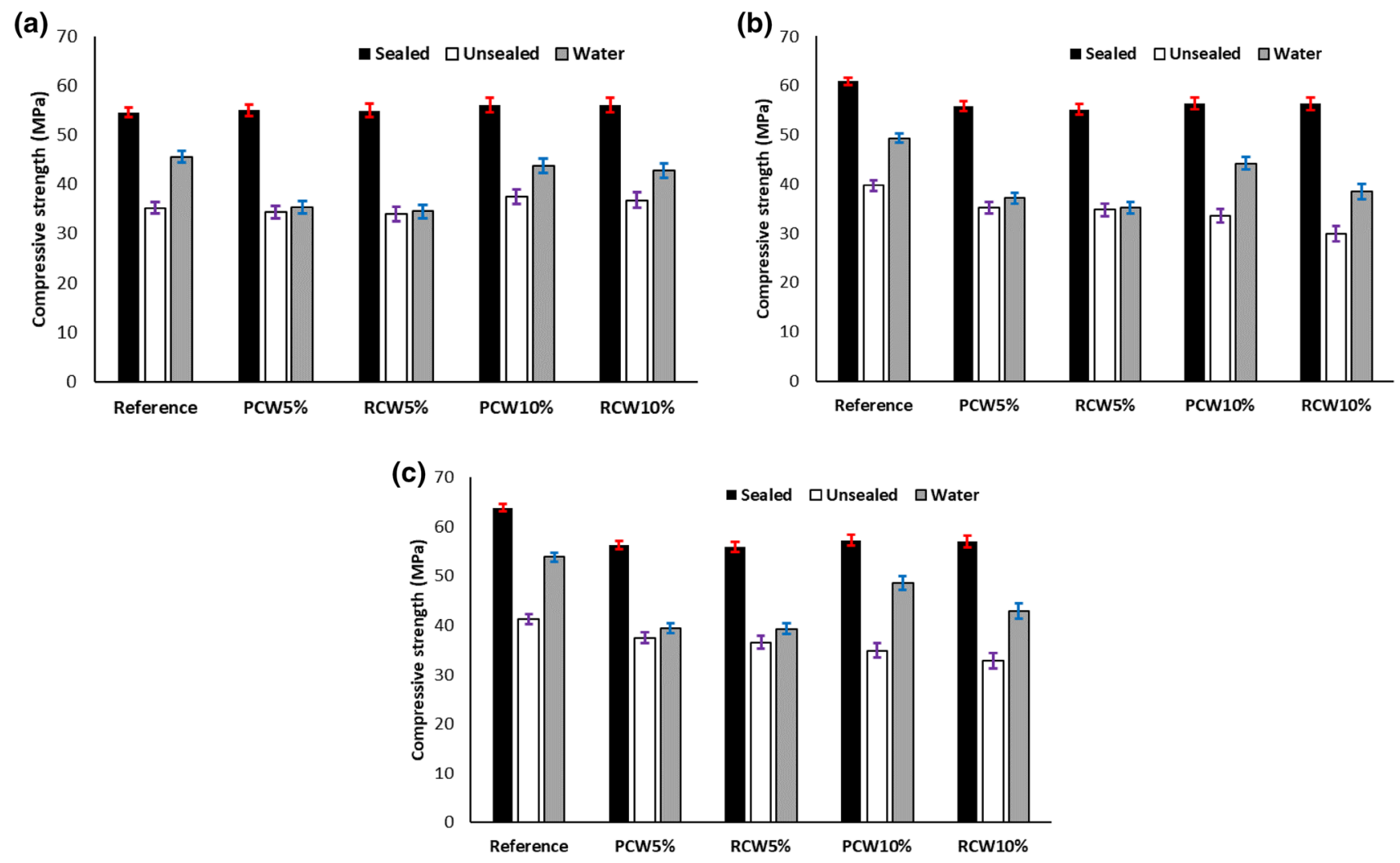

Fig. 3 Effects of replacing slag with two different ceramic wastes on the compressive strength at: a 7 days, b 14 days, c 28 days 
that replacement of slag up to $10 \%$ by ceramic wastes did not affect the compressive strength at the early age (7 days).

By increasing the curing duration from 7 to 14 days, no enhancement was recorded in the strength of the cured specimens with sealing except in the reference mixture, which had a $10 \%$ strength gain and reached $60 \mathrm{MPa}$. Increasing the ceramic waste led to a slight strength reduction in the specimens which were cured at the ambient temperature. Therefore, the minimum compressive strength was registered for the composition with $10 \%$ raw ceramic waste and it was around $30 \mathrm{MPa}$. At the final age (28 days), the strength was increased in almost all compositions by increasing curing time, regardless of the curing regime used and the content of ceramic wastes. In general, the final strength of mixtures was achieved after almost 7 days and curing prolongation had no remarkable influence on the strength gain, which can be attributed to the hardened nature of slag. This finding is in line with [50-53], as curing regime has substantial impact on the strength development. With regard to the results, sealing the specimens had superior effects on the enhancement of strength development.

Since the used binder mainly consisted of slag and this amorphous precursor is rich in calcium, it is therefore expected to mainly form a calcium aluminum silicate hydrate (C-A-S-H) gel in the matrix. Amorphous calcium silicate hydrates (A-C-S-H) mainly consists of disordered calcium silicate hydrate (C-S-H) gel and crystalline calcium silicate hydrates (C-C-S-H) gel, which consists of crystallized tobermorite [54]. Sealing the specimens could increase the chain length of the C-S-H gel and convert the unfavorable crystalline product $\alpha$-calcium silicate hydrate $\left(\alpha-\mathrm{C}_{2} \mathrm{SH}\right)$ to tobermorite. This can eventually result in decreasing the porosity, and result in an improvement in strength as well as bond properties at the interfacial transition zone (ITZ) between the matrix and aggregates [55-57]. Therefore, higher enhancement could be recorded for the sealed specimens compared to the other curing cases

\section{The Permeable Porosity}

The permeable porosity of different mix compositions is presented in Fig. 4. This assessment provides an indirect approach to evaluating the porosity network and a general idea about the influences of using different ceramic waste types, contents, and curing regimes on the pore structure of the compositions. Also, the pore structure and total porosity of specimens was investigated by the MIP test.

As was expected (and as shown in the results in Fig. 4), curing conditions greatly affected pore structure, so that the permeability porosity varied in the range of 5-7\%. The minimum porosity was measured for the sealed specimens regardless of the partial replacement of ceramic wastes, while using water or curing at the ambient conditions

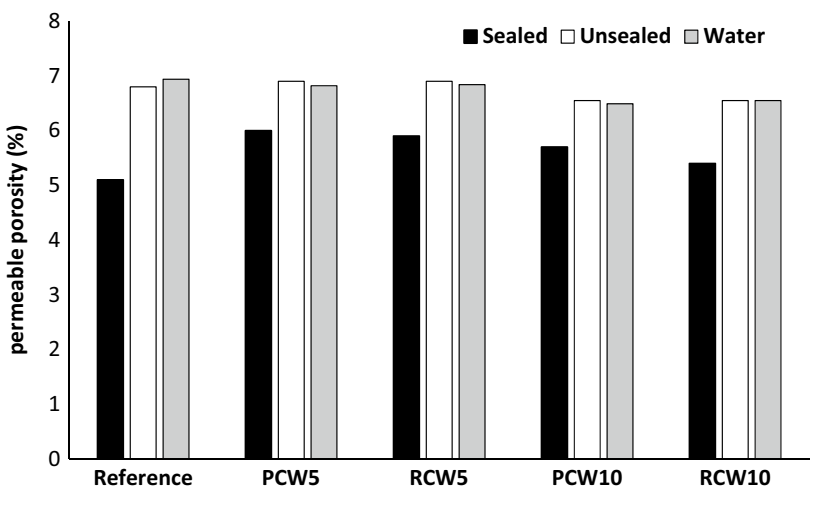

Fig. 4 Effect of using ceramic wastes as a replacement for slag on water absorption

showed no major efficacy. This means that sealing the specimens resulted in a higher content of chemical reactions and subsequently lower porosity compared to other curing regimes. According to the results, it was observed that using different curing regimes had a higher impact on the porosity than replacing slag with ceramic wastes. Interestingly, it was observed that increasing the content of ceramic wastes slightly reduced the permeability porosity, which could explain the slight increase in compressive strength.

\section{Mercury Intrusion Porosimetry (MIP) Test}

Total porosity, relative pore volume, and pore size distribution of samples were derived from the MIP test and are shown in Fig. 5. By comparing Fig. 5a, c, it is clear that the total porosity decreases and the pore size distribution curve shifts to smaller pore sizes as sealing was used to cure the specimens, indicating a denser microstructure of samples. Small pore sizes could be categorized in alkali-activated slag binders in the range of 3.1-50 nm [58, 59]. Therefore, the fraction volume of pores within this interval estimates the variation of small pores. Figure $5 \mathrm{~d}$ indicates the average pore sizes of the mix compositions. Interestingly, it was observed that curing in water led to minimizing the average pore sizes regardless of the mix compositions. Moreover, it was observed that unsealing the specimens resulted in the formation of large pore sizes.

Additionally, it was observed that the total porosity was increased by increasing the content of porcelain ceramic wastes regardless of the curing regime, while total porosity was reduced by increasing the content of raw ceramic wastes. As explained before, increasing the ceramic waste content from 5 to $10 \%$ led to the measurement of different impacts on the strength development. Therefore, the aim at this stage was to correlate total porosity and the recorded strengths at 28 days (Fig. 6). According to the analyzed results shown in Fig. 6, there is a poor correlation between 

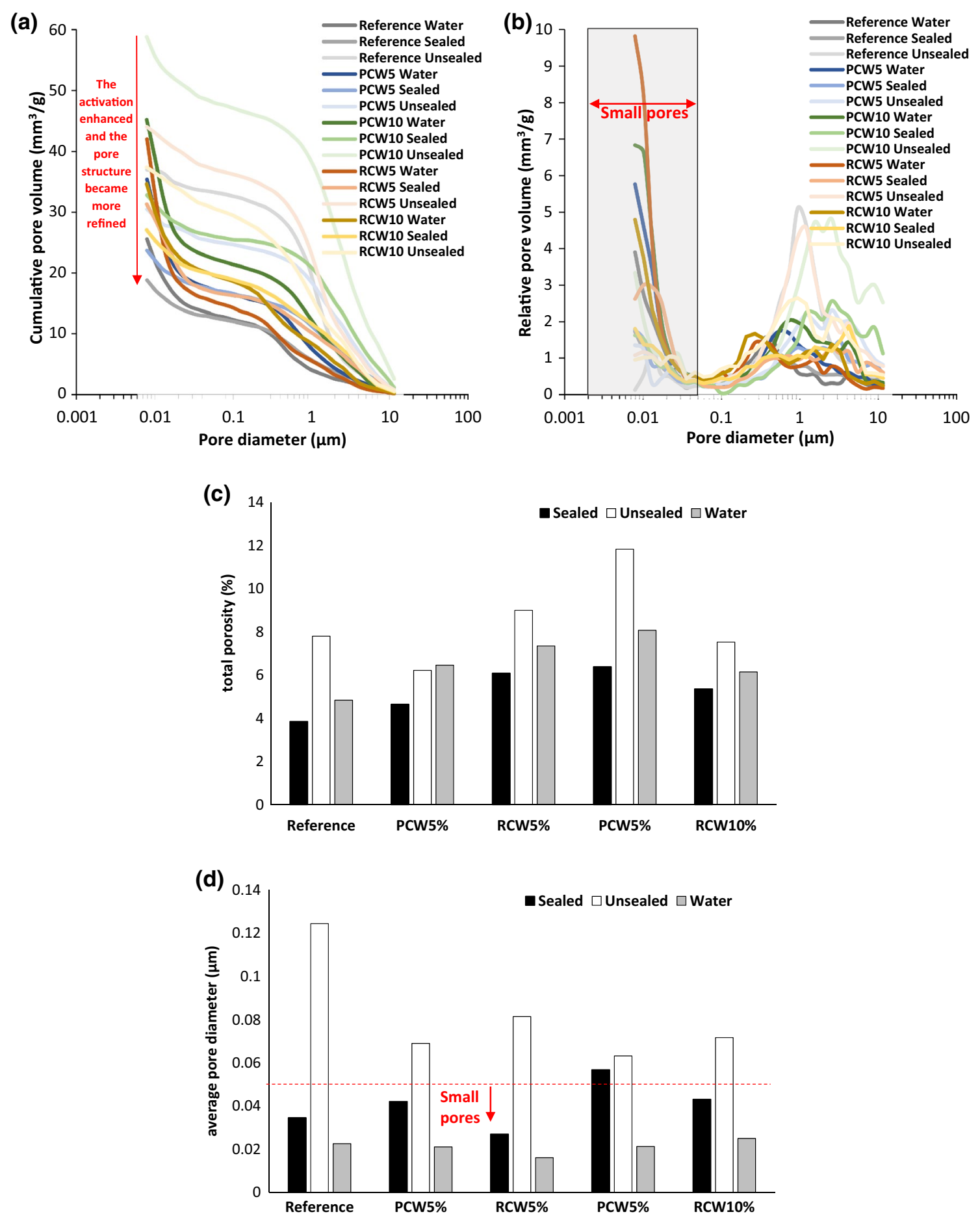

Fig. 5 MIP test results: a cumulative pore volume, $\mathbf{b}$ relative pore volume, $\mathbf{c}$ total porosity, $\mathbf{d}$ average pore diameter

the strength development and total porosity in the mix compositions with porcelain ceramic wastes, while there is an almost good correlation $\left(R^{2}>0.61\right)$ in the mix compositions with raw ceramic wastes.

\section{Thermogravimetric Analysis (TGA) and Differential Thermogravimetry (DTG)}

Figure 7 depicts weight loss and the derivative weight of mix compositions with different ceramic waste types and contents, and cured under different curing regimes. These 

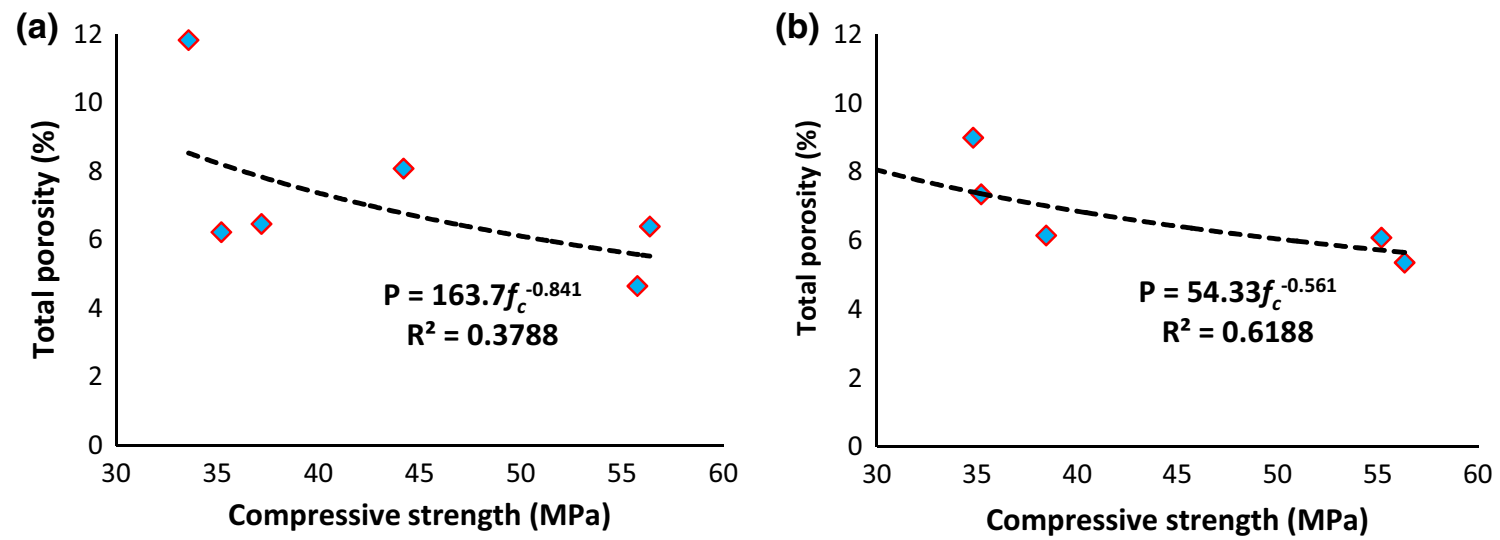

Fig. 6 Correlation between the strength and porosity for the mix compositions incorporating: a porcelain ceramic waste, $\mathbf{b}$ raw ceramic waste

Fig. 7 TGA and DTA analysis of the mix compositions containing ceramic wastes

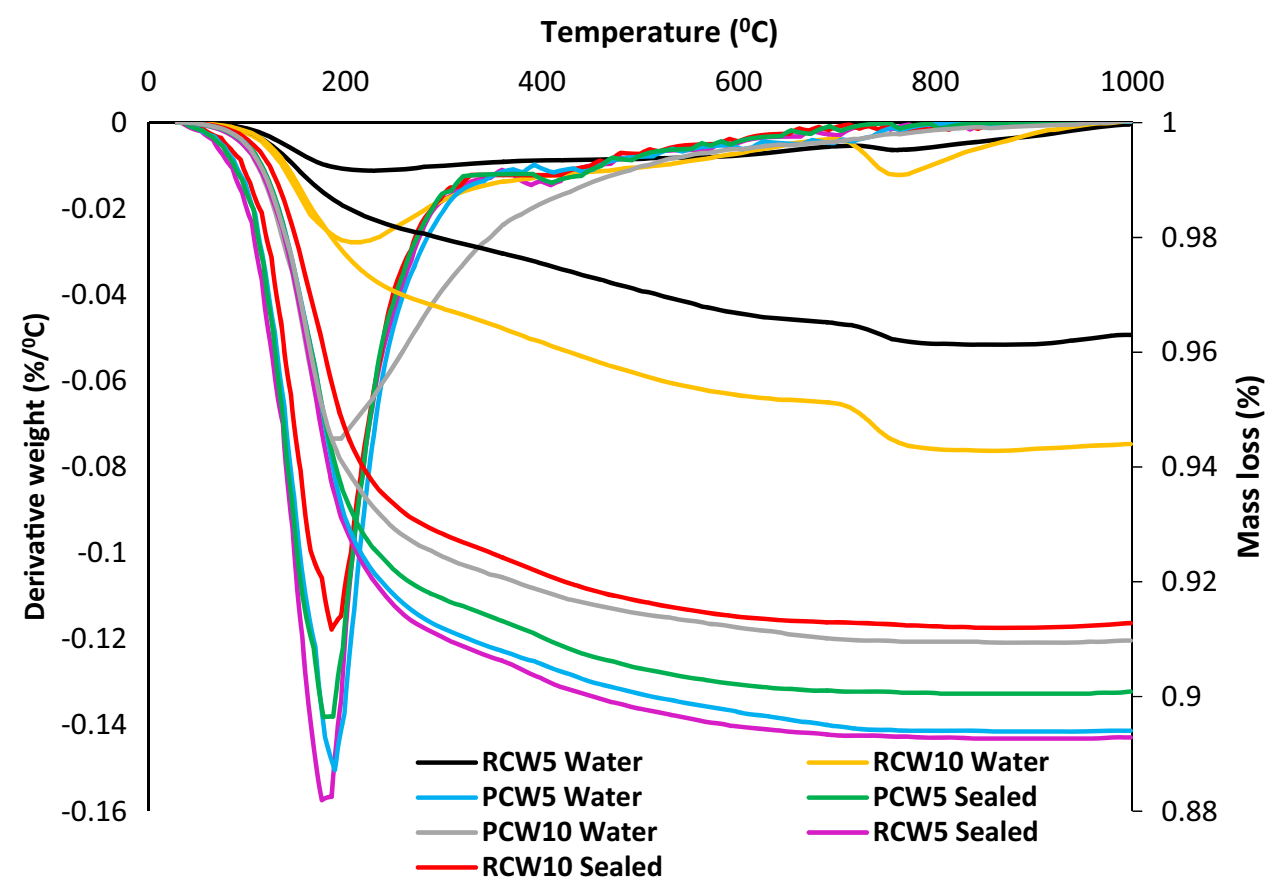

compositions were selected based on the maximum obtained strengths when using different contents of ceramic wastes.

Weight losses in TGA could be considered in the temperatures from 100 to $800{ }^{\circ} \mathrm{C}$ [60]. During the first stage, both free water and structurally bonded water are available in the composition. Then, the free water could be evaporated up to $100{ }^{\circ} \mathrm{C}$ temperature, and the weight loss from 100 to $800{ }^{\circ} \mathrm{C}$ is attributed to the structural water [55]. The mass loss rate slowed down after $250^{\circ} \mathrm{C}$ owing to the chemically bonded water and $\mathrm{OH}$ groups [61].

Regarding the differential thermogravimetry (DTA) curves, two major endothermic peaks at around 190 and $780{ }^{\circ} \mathrm{C}$ were observed; the large shoulder just below $200{ }^{\circ} \mathrm{C}$ is attributed to the dehydration of the calcium-rich silicate gel [62]. The second destruction phase (at $780{ }^{\circ} \mathrm{C}$ ) could be attributed to the decomposition of calcium carbonate $\left(\mathrm{CaCO}_{3}\right)$ [63]. The differences in the major endothermic peaks of the DTA curves indicate that some additional gel formation may have occurred owing to different curing regimes and ceramic waste types and contents. In addition, the DTG curves showed that the reduction of the peak corresponding to the calcium-rich silicate gel was responsible for the generation of $\mathrm{CaCO}_{3}$.

The results obtained by TGA and DTA analysis demonstrate that the chemical reactions in the mix compositions containing raw ceramic wastes were more sensitive to the used curing regimes compared to porcelain ceramic wastes. For instance, the cured specimens with 5\% raw ceramic wastes in a water tank showed the minimum mass loss (4\%), while the maximum mass loss was measured for 


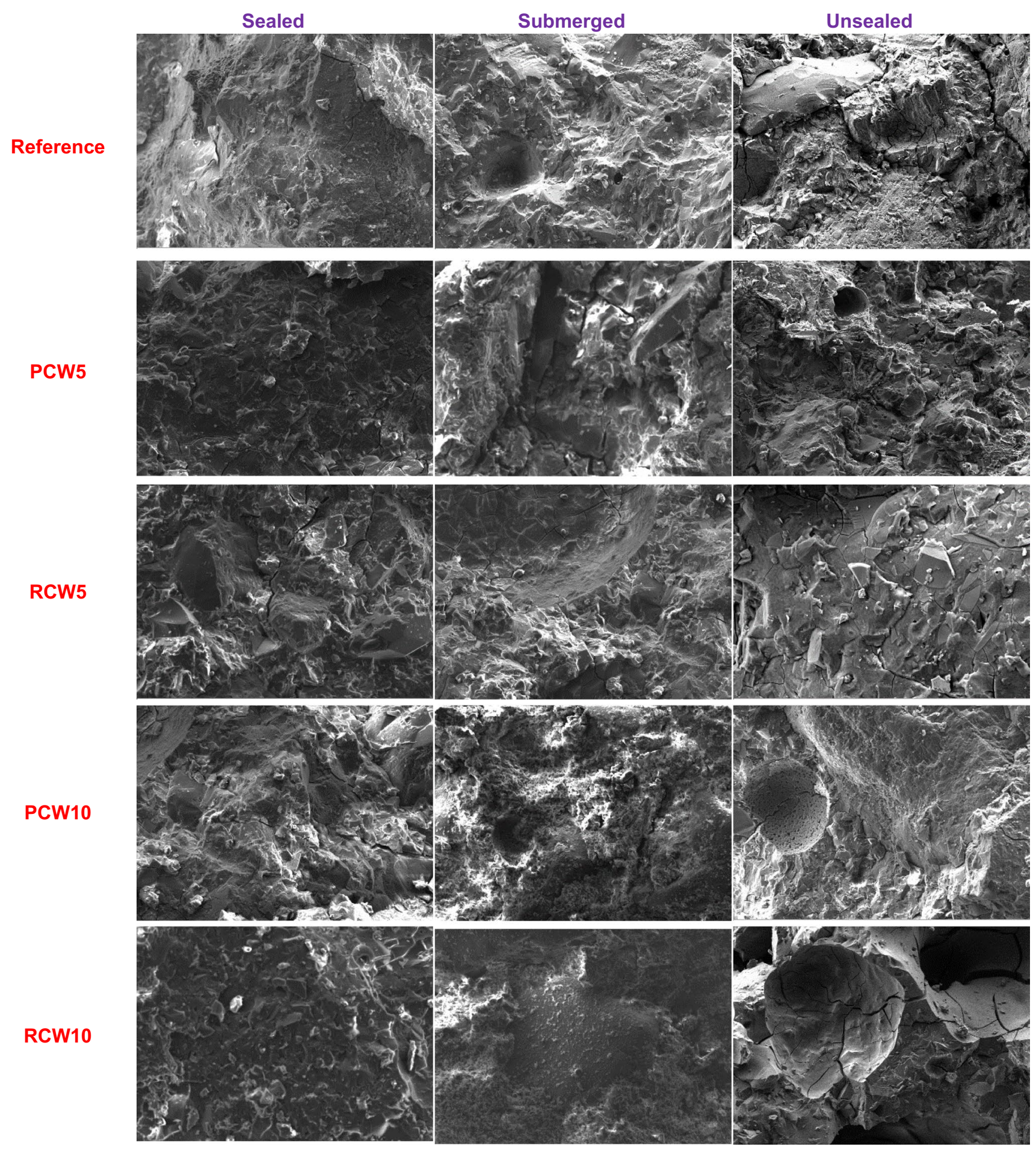

Fig. 8 SEM images from the surface of specimens with $\times 400$ magnification

the specimen cured just with sealing (11\%). In contrast, the specimen incorporating porcelain ceramic waste with different curing regimes and ceramic waste content showed around a $2 \%$ difference in the recorded maximum (91\%) and minimum (89\%) mass loss.
The results achieved from TGA and DTA analyses suggest that raw ceramic waste participated in the chemical reactions and gel formation, while porcelain ceramic wastes were partial participants in chemical reactions (due to their having a coating layer). 


\section{Microstructural Analysis}

\section{SEM/EDX Analysis}

The effect of using various curing regimes and ceramic wastes on the morphology of specimens is indicated in Fig. 8. As shown, the previously mentioned effective parameters greatly impacted the matrix morphologies. Regardless of ceramic waste type and content, sealing the specimens resulted in a very dense matrix, which could explain the higher strengths compared to other curing conditions. Interestingly, it was found that using unsealed curing conditions led to the formation of some cracks in the matrix, and these cracks were observed more often in the matrices with raw ceramic wastes compared to porcelain ceramics. This is perhaps a result of higher water absorption of raw ceramic wastes compared to porcelain ceramic wastes.

More exhaustive EDX analyses were carried out to determine the composition of the gel phases using the molar ratios of $\mathrm{Al}_{2} \mathrm{O}_{3} / \mathrm{SiO}_{2}$ and $\mathrm{CaO} / \mathrm{SiO}_{2}$ (see Fig. 9). In addition, a comparison was conducted on the calculated molar ratios of the mix compositions without curing condition effects, as well as the measured molar ratios in the mix compositions by EDX analysis with consideration of the curing conditions. The comparative analysis shows that the calculated molar ratios (regardless of curing effects), indicate an almost constant $\mathrm{Al}_{2} \mathrm{O}_{3} / \mathrm{SiO}_{2}$ ratio, while the ratio of $\mathrm{CaO} / \mathrm{SiO}_{2}$ changed. The EDX analysis showed that both $\mathrm{Al}_{2} \mathrm{O}_{3} / \mathrm{SiO}_{2}$ and $\mathrm{CaO} /$ $\mathrm{SiO}_{2}$ ratios were varied in the mix compositions by considering the effects of curing conditions. It was found that the maximum molar ratios of $\mathrm{Al}_{2} \mathrm{O}_{3} / \mathrm{SiO}_{2}$ and $\mathrm{CaO} / \mathrm{SiO}_{2}$ were detected in the reference mix composition sealed with plastic bag, while curing in the water and unsealing reduced both these molar ratios. Moreover, replacing slag with ceramic wastes reduced both $\mathrm{Al}_{2} \mathrm{O}_{3} / \mathrm{SiO}_{2}$ and $\mathrm{CaO} / \mathrm{SiO}_{2}$. As aforementioned earlier, sealing affects the temperature-dependent chemical reactions, therefore, lower reduction was noticed for both $\mathrm{Al}_{2} \mathrm{O}_{3} / \mathrm{SiO}_{2}$ and $\mathrm{CaO} / \mathrm{SiO}_{2}$ for specimens were cured by sealing compared to other curing approaches, regardless of the ceramic content and type. Similar to the results obtained for the calculated molar ratios, effects of replacing slag with ceramic wastes and using different curing regimes had higher impact on molar ratio $\mathrm{CaO} / \mathrm{SiO}_{2}$ than $\mathrm{Al}_{2} \mathrm{O}_{3}$ / $\mathrm{SiO}_{2}$. The curing regime affects the dissolution rate of silicate and aluminate species and consequently, it affects the substantial content of calcium through ion-exchange. Therefore, it affects the molar ratios obtained from EDX analyses, while it was assumed in calculation that all materials could be fully soluble. Furthermore, according to the results shown in Fig. 9, the points clustered primarily in the ranges characteristic of C-A-S-H gel [64].

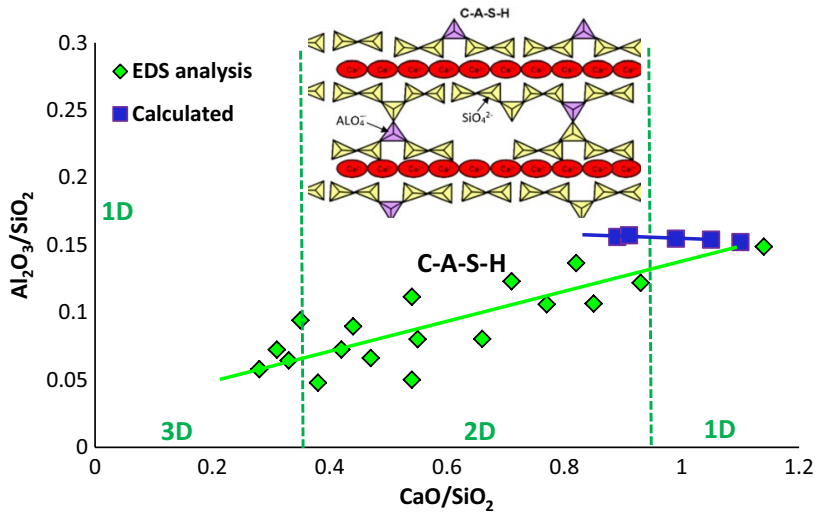

Fig. $9 \mathrm{Al}_{2} \mathrm{O}_{3} / \mathrm{SiO}_{2}$ versus $\mathrm{CaO} / \mathrm{SiO}_{2}$ ratios for gels precipitating in alkali-activated binders (1D, 2D and 3D refer to connectivity and degree of condensation of the alumino-silicate structure in the C-AS-H gel)

\section{Mineralogical Alteration by an XRD Analysis}

The impacts of different curing regimes (water and sealed) on the crystalline- and quantitative-phase analysis are shown in Fig. 10. With regard to the results, the major crystalline phases were noted for quartz $\left(\mathrm{SiO}_{2}\right)$, regardless of the curing regimes and ceramic wastes. Although some peaks of albite $\left(\mathrm{NaAlSi}_{3} \mathrm{O}_{8}\right)$ and anorthite $\left(\mathrm{CaAl}_{2} \mathrm{Si}_{2} \mathrm{O}_{8}\right)$ were found, their peaks were significantly less intense compared to quartz. Reference mix compositions showed more amorphous phases and when slag was replaced with raw ceramic wastes, an increase in the intensity of the characteristic diffraction peaks was observed, which means a higher degree of crystallization was obtained. In comparison, the addition of porcelain ceramic waste had no impact on the formation of the crystalline phases. This finding is in line with the results obtained by TGA/DTA and SEM/EDX analysis, which proposed the feasibility of participation of raw ceramic waste in the chemical reactions and gel formations, while porcelain ceramic wastes partially participated in the chemical reactions. In general, the diffraction patterns of compositions were governed by the ceramic waste type, while curing method did not change the mineralogical phases significantly.

Figure 10b illustrates the quantitative phase analysis by the Rietveld method, where the results are normalized to $100 \%$. The major phase in pastes was amorphous $(>70$ $\mathrm{wt} \%)$, while the major crystalline phases was formed by quartz (16 wt $\%$ up to $22 \mathrm{wt} \%$ ). Higher content of the amorphous phase in the same mix compositions could be attributed to the impacts of curing conditions on the chemical reactions. By using ceramic wastes instead of slag, the content of quartz increased. This can explain the strength loss of the compositions containing ceramic wastes compared to alkali-activated slag-based binders. 
(a)

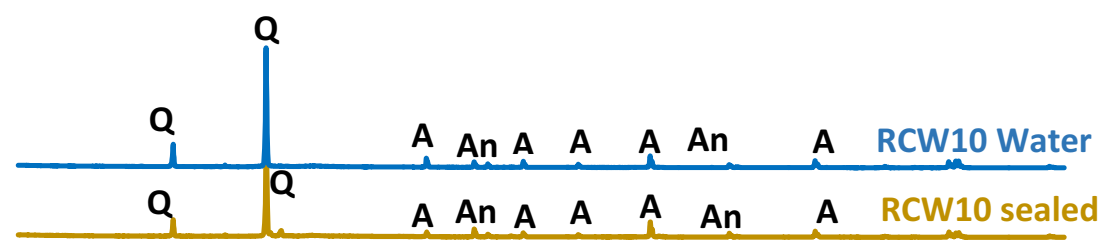

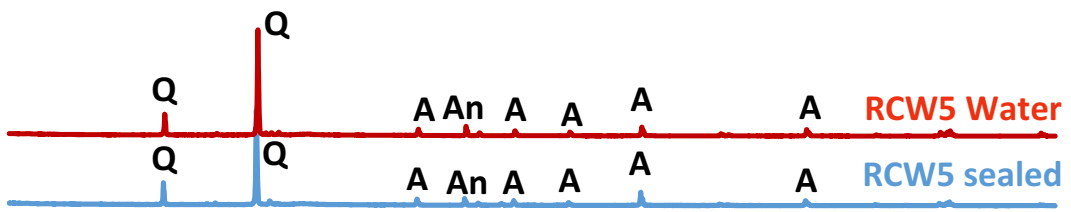

\begin{tabular}{llllll}
$\mathbf{Q}$ & $\mathbf{Q}$ & & & & PCW10 water \\
$\mathbf{Q}$ & $\mathbf{Q}$ & A An & A & A & PCW10 sealed \\
\hline
\end{tabular}

\begin{tabular}{lllllll}
$\mathbf{Q}$ & $\mathbf{Q}$ & & & & & PCW5 water \\
$\mathbf{Q}$ & $\mathbf{Q}$ & A & An A & A & A & PCW5 sealed \\
\hline
\end{tabular}

\begin{tabular}{rr}
$Q_{A}$ & REF water \\
\hline Q $_{\text {A }}$ & REF sealed \\
\hline
\end{tabular}

\begin{tabular}{lllllllll}
\hline 10 & 20 & 30 & 40 & 50 & 60 & 70 & 80 & 90
\end{tabular}

(b)

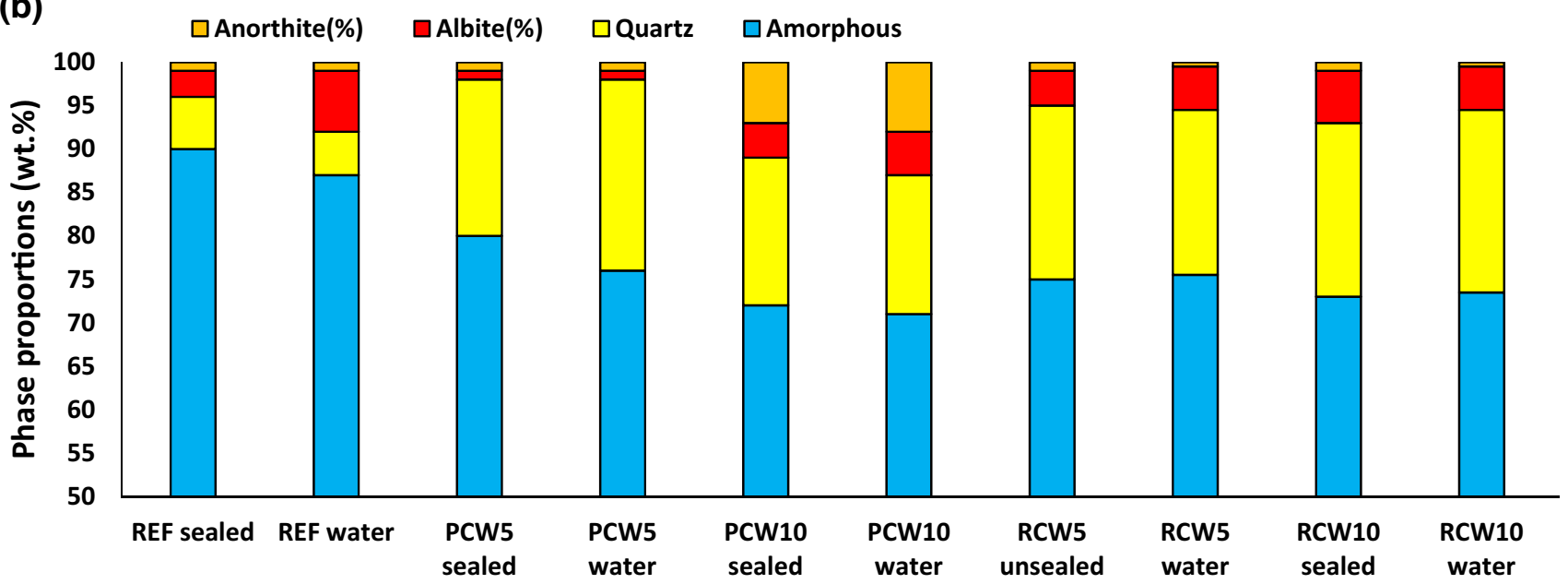

Fig. 10 a XRD analysis for compositions (Q-Quartz, A-Albite, and An: Anorthite), b quantitative phase analysis by the Rietveld method 


\section{Heat of Hydration}

To evaluate the effects of using ceramic wastes instead of slag on the hydration kinetics, a heat flow calorimetry test was carried out. Figure 11 shows the results of the heat flow calorimetry test. The results showed that for the first $24 \mathrm{~h}$, utilizing ceramic wastes increased the total heat of hydration, compared to the reference mix composition using $100 \%$ slag. After $24 \mathrm{~h}$, the differences among heat of hydration of different mix compositions containing ceramic wastes disappeared and become less than the heat flow evolution of an alkali-activated slag system.

In Fig. 11, the first peak is followed by a dormant (or induction) period, in which the concentration of soluble alumina and silica species increases up to a certain threshold value $[9,65,66]$.

The use of higher temperatures caused the pastes containing ceramic wastes to produce soluble silica species. Bernal indicated that increasing metakaolin resulted in the release of higher reaction heats, indicating that the kinetics of reaction are strongly affected by the inclusion of this material [67].

Replacement of slag with ceramic wastes consistently increased the temperature raised from the pastes in the first $24 \mathrm{~h}$, and this increased the feasibility of thermal cracking. On a qualitative level, the broad peak and the longer exothermal activity reflect a slower hydration of the alkali- activated slag system, leading to lower early strength. This finding is in line with the recorded compressive strengths at the early ages (see Fig. 3a).

\section{Conclusions}

This investigation reported on the effects of using different curing regimes (sealing with plastic bags, unsealed, water bath) on alkali-activated slag binders, in which slag was

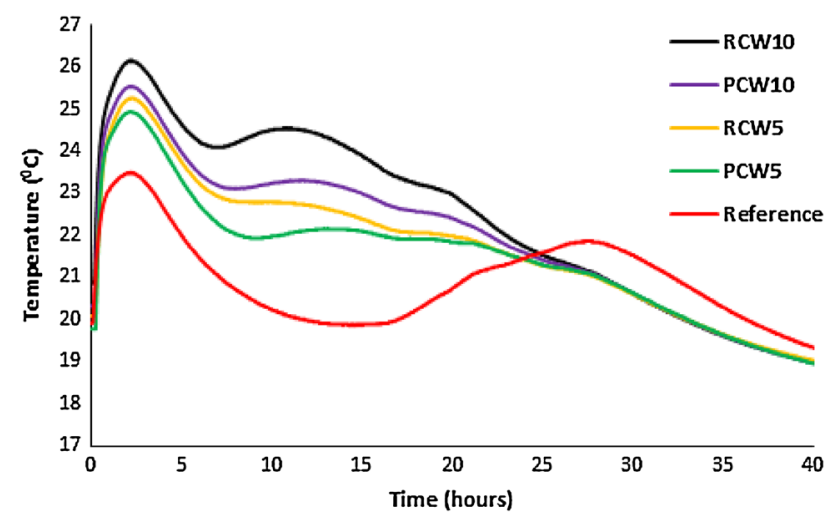

Fig. 11 Impacts of replacing slag with ceramic wastes on the heat of hydration partially replaced by two different ceramic wastes (unfired or fired). The effects of these parameters on the strength development and microstructure of the mixtures were studied. The following findings could be highlighted:

1. Regardless of ceramic waste type and content, the highest compressive and flexural strength was observed in the specimens cured with sealing using plastic bags. The lowest strengths, regardless of curing duration, were measured in the specimens cured at ambient conditions (unsealed).

2. Curing conditions greatly affected the permeability porosity, so that the minimum porosities were measured for the sealed specimens (regardless of the partial replacement of ceramic wastes), while using water or curing at the ambient conditions had no major effect. Moreover, it was observed that using different curing regimes had a higher impact on the porosity than replacing slag with ceramic wastes.

3. The results of the MIP test showed that curing in water led to minimizing the average pore sizes, while unsealing the specimens resulted in the formation of large pore sizes.

4. Regardless of the curing regimes, the total porosity obtained from the MIP test was governed by the ceramic type, so that total porosity was increased by increasing the content of fired ceramic wastes, while it was reduced by increasing the content of unfired ceramic wastes.

5. A poor correlation between the strength development and total porosity in the mix compositions with fired ceramic wastes was observed, while better correlation existed in the mix compositions with unfired ceramic wastes.

6. SEM images showed that unsealing led to the formation of some cracks in the matrix, and these cracks were observed more frequently in the matrices with raw ceramic wastes compared to porcelain ceramics. This may be justified by a higher water absorption of raw ceramic wastes compared to porcelain ceramic wastes.

7. Regardless of the curing conditions, alkali-activated slag binders demonstrated more amorphous phases compared to mixtures containing ceramic wastes. Replacing slag with raw ceramic wastes increased the intensity and the characteristic diffraction peaks, which indicates a higher degree of crystallization, while the addition of porcelain ceramic waste had no impact on the formation of the crystalline phases.

8. The microstructural analysis proposed the feasibility of using raw ceramic waste in the chemical reactions and gel formations, while porcelain ceramic wastes partially participated in the chemical reactions. 
The findings of this study demonstrate that satisfactory mechanical properties can be obtained in alkaliactivated slag/ceramic binders without using thermal curing conditions, in order to minimize energy consumption, cost, and $\mathrm{CO}_{2}$ emissions. As large quantities of ceramic materials are generated as construction and demolition wastes, the results presented in this study provide information on the feasibility of using ceramic waste in one-part alkali-activated slag/ceramic binders in large-scale applications. Further investigations must be carried out on the durability performance and longterm performance of these binders.

Acknowledgements Open access funding provided by University of Oulu including Oulu University Hospital. The authors sincerely appreciate the Finnish Funding Agency for Technology and Innovation (Tekes) and Mattonurminen Company to support the GEOBIZ project with Grant ID: 1105/31/2016.

\section{Compliance with Ethical Standards}

Conflict of interest The authors declare that there is no conflict of interests regarding the publication of this paper.

Open Access This article is distributed under the terms of the Creative Commons Attribution 4.0 International License (http://creativeco mmons.org/licenses/by/4.0/), which permits unrestricted use, distribution, and reproduction in any medium, provided you give appropriate credit to the original author(s) and the source, provide a link to the Creative Commons license, and indicate if changes were made.

\section{References}

1. Attanasio, A., Pascali, L., Tarantino, V., Arena, W., Largo, A.: Alkali-activated mortars for sustainable building solutions: effect of binder composition on technical performance. Environments $\mathbf{5}$, 35 (2018). https://doi.org/10.3390/environments5030035

2. Majidi, B.: Geopolymer technology, from fundamentals to advanced applications: a review. J. Mater. Technol. 24, 79-87 (2009)

3. Torres-Carrasco, M., Rodríguez-Puertas, C., Alonso, M., Puertas, F.: Alkali activated slag cements using waste glass as alternative activators. Rheological behavior. J. Span. Ceram. Glass Soc. 54, 45-57 (2015)

4. Somna, K., Jaturapitakkul, C., Kajitvichyanukul, P., Chindaprasirt, $\mathrm{P} .: \mathrm{NaOH}$-activated ground fly ash geopolymer cured at ambient temperature. Fuel 90, 2118-2124 (2011)

5. Torres-Carrasco, M., Puertas, F.: Waste glass in the geopolymer preparation mechanical and microstructural characterization. J. Clean. Prod. 90, 397-408 (2015)

6. Luukkonen, T., Abdollahneja, Z., Yliniemi, J., Kinnunen, P., Illikainen, M.: One-part alkali-activated materials: a review. Cem. Concr. Res. 103, 21-34 (2018)

7. Duxson, P., Provis, J.: Designing precursors for geopolymer cements. J. Am. Ceram. Soc. 91, 3864-3869 (2008)

8. Balo, A.M., Rahier, H., Mobili, A., Katsiki, A., Fagel, N., Chinje, U.M., Njopwouo, D.: Metakaolin-based inorganic polymer synthesis using cotton shell ash as sole alkaline activator. Constr. Build. Mater. 191, 1011-1022 (2018)

9. Luukkonen, T., Abdollahneja, Z., Yliniemi, J., Kinnunen, P., Illikainen, M.: Comparison of alkali and silica sources in onepart alkali-activated blast furnace slag mortar. J. Clean. Prod. 187, 171-179 (2018)

10. Ghafoori, N., Najimi, M., Radke, B.: Natural Pozzolan-based geopolymers for sustainable construction. Environ. Earth Sci. 75, 1110 (2016). https://doi.org/10.1007/s12665-016-5898-5

11. Hajimohammadi, A., Ngo, T., Mendis, P., Kashani, A., van Deventer, J.S.J.: Alkali activated slag foams: the effect of the alkali reaction on foam characteristics. J. Clean. Prod. 147, 330-339 (2017)

12. Collins, F., Sanjayan, J.G.: Microcracking and strength development of alkali activated slag concrete. Cem. Concr. Compos. 23, 345-352 (2001)

13. van Deventer, J.S.J., Feng, D., Duxson, P.: Dry mix cement composition, methods and system involving same. US Patent 7,691,198 B2 (2010)

14. Li, X., Wang, Z., Jiao, Z.: Influence of curing on the strength development of calcium-containing geopolymer mortar. Materials 6, 5069-5076 (2013)

15. Arbi, K., Nedeljković, M., Zuo, Y., Ye, G.: A review on the durability of alkali-activated fly Ash/slag systems: advances, issues, and perspectives. Ind. Eng. Chem. Res. 55, 5439-5453 (2016)

16. Yang, K., Song, J., Song, K.: Assessment of $\mathrm{CO}_{2}$ reduction of alkali-activated concrete. J. Clean. Prod. 39, 265-272 (2013)

17. Collins, F., Sanjayan, J.: Effect of pore size distribution on drying shrinking of alkali activated slag concrete. Cem. Concr. Res. 30, 1401-1406 (2000)

18. Weil, M., Dombrowski, K., Buchawald, A.: Life-cycle analysis of geopolymers. Woodhead Publishing Limited Abington Hall, Cambridge (2009)

19. McLellan, B., Williams, R., Lay, J., Van Riessen, A., Corder, G.: Costs and carbon emissions for geopolymer pastes in comparison to ordinary Portland cement. J. Clean. Prod. 19, 1080-1090 (2011)

20. Najimi, M., Ghafoori, N., Sharbaf, M.: Alkali-activated natural pozzolan/slag mortars: a parametric study. J. Constr. Build. Mater. 164, 625-643 (2018)

21. Mastali, M., Kinnunen, P., Isomoisio, H., Karhu, M., Illikainen, M.: Mechanical and acoustic properties of fiber-reinforced alkaliactivated slag foam concretes containing lightweight structural aggregates. Constr. Build. Mater. 187, 371-381 (2018)

22. Lee, N.K., Lee, H.K.: Setting and mechanical properties of alkaliactivated fly ash/slag concrete manufactured at room temperature. Constr. Build. Mater. 47, 1201-1209 (2013)

23. Jang, J.G., Lee, N.K., Lee, H.K.: Fresh and hardened properties of alkali-activated fly ash/slag pastes with superplasticizers. Constr. Build. Mater. 50, 169-176 (2014)

24. Yao, X., Yang, T., Zhang, Z.: Compressive strength development and shrinkage of alkali-activated fly ash-slag blend associated with efflorescence. Mater. Struct. 49, 1-12 (2015)

25. Rashed, A.M.: Properties of alkali-activated fly ash concrete blended with slag. Iran. J. Mater. Sci. Eng. 10, 57-64 (2015)

26. Shen, W., Wang, Y., Zhang, T., Zhou, M., Li, J., Cui, X.: Magnesia modification of alkali activated slag fly ash cement. J. Wuhan Univ. Technol. Mater. Sci. 26, 121-125 (2011)

27. Marjanović, N., Komljenovića, M., Baščarevića, Z., Nikolića, V., Petrovićb, R.: Physical-mechanical and microstructural properties of alkali-activated fly ash-blast furnace slag blends. Ceram. Int. 41, 1421-1435 (2015)

28. Gao, X., Yu, Q.L., Brouwers, H.J.H.: Assessing the porosity and shrinkage of alkali activated slag-fly ash composites designed applying a packing model. Constr. Build. Mater. 119, 175-184 (2016) 
29. Weiguo, S..,Yiheng, W., Tao, Z., Mingkai, Z., Jiasheng, L., Xiaoyu, C.: Magnesia modification of alkali-activated slag fly ash cement. Wuhan Univ. Technol. Mater. Sci. 26, 121-125 (2011)

30. Abdollahnejad, Z., Mastali, M., Mastali, M., Dalvand, A.: A comparative study on the effects of recycled glass fiber on drying shrinkage rate and mechanical properties of the self-compacting concrete and fly ash/slag geopolymer concrete. J. Mater. Civil Eng. 29(8), 040107076 (2017)

31. Lecomte, I., Henrist, C., Liegeois, M., Maseri, F., Rulmont, A., Cloots, R.: (Micro)-structural comparison between geopolymers, alkali activated slag cement and Portland cement. J. Eur. Ceram. Soc. 26, 3789-3797 (2006)

32. Lloyd, R.R.: Accelerated ageing of geopolymers. In: Provis, J.L., van Deventer J.S.J. (eds.) Geopolymers: structures, processing, properties and industrial applications, p. 139. Woodhead, Cambridge (2009)

33. Mobili, A., Belli, A., Giosuè, C., Bellezze, T., Tittarelli, F.: Metakaolin and fly ash alkaliactivated mortars compared with cementitious mortars at the same strength class. Cem. Concr. Res. 88, 198-210 (2016)

34. Reig, L., Tashim, M.M., Soriano, L., Borracher, M.V., Monzó, J., Payá, J.: Alkaline activation of ceramic waste materials. Waste Biomass Valoriz. 4, 729-736 (2013)

35. Zimbili, O., Salim, W., Ndambuki, M.: A review on the usage of ceramic wastes in concrete production. Int. J. Civil Environ. Struct. Constr. Archit. Eng. 8, 91-95 (2014)

36. Lavat, A.E., Trezza, M.A., Poggi, M.: Characterization of ceramic roof tile wastes as pozzolanic admixture. Waste Manag. 29, 16661674 (2009)

37. Nuran, A., Mevlut, U.: The use of waste ceramic tile in cement production. Cem. Concr. Res. 30, 497-499 (2000)

38. Pereira-de-Oliveira, L.A., Castro-Gomes, J.P., Santos, P.M.S.: The potential pozzolanic activity of glass and red-clay ceramic waste as cement mortars components. Constr. Build. Mater. 31, 197-203 (2012)

39. Van Deventer, J.S.J., Provis, J.L., Duxson, P., Brice, D.G.: Chemical research and climate change as drivers in the commercial adoption of alkali activated materials. Waste Biomass Valoriz. 1, 145-155 (2010)

40. Van Deventer, J.S.J., Provis, J.L., Duxson, P., Lukey, G.C.: Reaction mechanisms in the geopolymeric conversion of inorganic waste to useful products. J. Hazard Mater. 139, 506-513 (2007)

41. Duxson, P., Fernández-Jiménez, A., Provis, J.L., Lukey, G.C., Palomo, A., van Deventer, J.S.J.: Geopolymer technology: the current state of the art. J. Mater. Sci. 42, 2917-2993 (2007)

42. Puertas, F., García-Díaza, I., Barbab, A., Gazullab, M.F., Palaciosa, M., Gomez, M.P., Martínez-Ramíreza, S.: Ceramic wastes as alternative raw materials for Portland cement clinker production. Cem. Concr. Compos. 30, 798-805 (2008)

43. Reig, L., Sanz, M.A., Borrachero, M.V., Monzo, J., Soriano, L., Paya, J.: Compressive strength and microstructure of alkali activated mortars with high ceramic waste content. Ceram. Int. 43, 13622-13634 (2017)

44. Pacheco-Torgal, F., Jalali, S.: Reusing ceramic wastes in concrete. Constr. Build. Mater. 24, 832-838 (2010)

45. ASTM D6913/D6913M-17: Standard test methods for particlesize distribution (gradation) of soils using sieve analysis. ASTM International, West Conshohocken (2017). http://www.astm.org

46. ASTM C116-90, Test Method for Compressive Strength of Concrete Using Portions of Beams Broken in Flexure (Withdrawn 1999), ASTM International, West Conshohocken, PA, 1990. http://www.astm.org

47. ASTM C293/C293M-16, Standard Test Method for Flexural Strength of Concrete (Using Simple Beam With Center-Point Loading), International, A.S.T.M., West Conshohocken, PA, 2016. http://www.astm.org
48. Lee, S., Van Riessen, A., Chon, C.M.: Benefits of sealed-curing on compressive strength of fly ash-based geopolymers. Materials (2016). https://doi.org/10.3390/ma9070598

49. Suwan, T., Fan, M.: Effect of manufacturing process on the mechanisms and mechanical properties of fly ash-based geopolymer in ambient curing temperature. Mater. Manuf. Process. 32, 461-467 (2017)

50. Akçaözoglu, S., Ulu, C.: Recycling of waste PET granules as aggregate in alkali-activated blast furnace slag/metakaolin blends. Constr. Build. Mater. 58, 31-37 (2014)

51. Altan, E., Erdogan, S.T.: Alkali activation of a slag at ambient and elevated temperatures. Cem. Concr. Compos. 34, 131-139 (2012)

52. Bernal, S.A., Gutierrez, R.M., Provis, J.L., Rose, V.: Effect of silicate modulus and metakaolin incorporation on the carbonation of alkali silicate-activated slags. Cem. Concr. Res. 40, 898-907 (2010)

53. Aydın, S., Baradan, B.: The effect of fiber properties on high performance alkali activated slag/silica fume mortars. Compos. B 45, 63-69 (2013)

54. Zeng, L., Yang, L., Wang, S., Yang, K.: Synthesis and characterization of different crystalline calcium silicate hydrate: application for the removal of aflatoxin B1 from aqueous solution. J. Nanomater. 431925, 10 (2014). https://doi.org/10.1155/2014/431925

55. Masse, S., Zanni, H., Lecourtier, J., Roussel, J.C., Rivereau, A.: ${ }^{29} \mathrm{Si}$ solid state NMR study of tricalcium silicate and cement hydration at high temperature. Cem. Concr. Res. 23, 1169-1177 (1993)

56. Yang, Q., Zhang, S., Huang, S., He, Y.: Effect of ground quartz sand on properties of high-strength concrete in the steam-autoclaved curing. Cem. Concr. Res. 30, 1993-1998 (2000)

57. Aldea, C.M., Young, F., Wang, K., Shah, S.P.: Effects of curing conditions on properties of concrete using slag replacement. Cem. Concr. Res. 30, 465-472 (2000)

58. Fang, G., Bahrami, H., Zhang, M.: Mechanisms of autogenous shrinkage of alkali-activated fly ash-slag pastes cured at ambient temperature within 24 h. Constr. Build. Mater. 171, 377-387 (2018)

59. IUPAC, Manual of symbols and terminology for physicochemical quantities and units, appendix 2, part 2, Colloid and Surface Chemistry, International Union of Pure and Applied Chemistry, 1976

60. Li, N., Shi, C., Wang, Q., Zhang, Z., Ou, Z.: Composition design and performance of alkali-activated cements. Mater. Struct. (2017) https://doi.org/10.1617/s11527-017-1048-0

61. Nath, S.K., Maitra, S., Mukherjee, S., Kumar, S.: Microstructural and morphological evolution of fly ash based geopolymers. Constr. Build. Mater. 111, 758-765 (2016)

62. Alarcon-Ruiz, L., Platret, G., Massieu, E., Ehrlacher, A.: The use of thermal analysis in assessing the effect of temperature on a cement paste. Cem. Concr. Res. 35, 609-613 (2005)

63. Shaikh, F.U.A., Supit, S.W.M.: Mechanical and durability properties of high volume fly ash (HVFA) concrete containing calcium carbonate $\left(\mathrm{CaCO}_{3}\right)$ nanoparticles. Constr. Build. Mater. 70, 309-321 (2014)

64. Garcia-Lodeiro, I., Palomo, A., Fernández-Jiménez, A., Macphee, D.E.: Compatibility studies between N-A-S-H and C-A-S-H gels. Study in the ternary diagram $\mathrm{Na}_{2} \mathrm{O}-\mathrm{CaO}-\mathrm{Al}_{2} \mathrm{O}_{3}-\mathrm{SiO}_{2}-\mathrm{H}_{2} \mathrm{O}$. Cem. Concr. Res. 41, 923-931 (2011)

65. Sun, Z., Vollpracht, A.: Isothermal calorimetry and in-situ XRD study of the $\mathrm{NaOH}$ activated fly ash, metakaolin and slag. Cem. Concr. Res. 103, 110-122 (2018)

66. Gruskovnjak, A., Lothenbach, B., Holzer, L., Figi, R., Winnefeld, F.: Hydration of alkali-activated slag: comparison with ordinary Portland cement. Adv. Cem. Res. 18, 119-128 (2006)

67. Bernal, S.: Effect of the activator dose on the compressive strength and accelerated carbonation resistance of alkali silicate-activated slag/metakaolin blended materials. Constr. Build. Mater. 98, 217-226 (2015)

Publisher's Note Springer Nature remains neutral with regard to jurisdictional claims in published maps and institutional affiliations. 